\title{
CIHR cuts grants for in-depth health journalism to focus on social media
}

$\mathrm{F}$ ewer complex health research stories will make it to light now that the Canadian Institutes of Health Research (CIHR) has shuttered a highly prized journalism grant, past recipients warn.

Each year, the now defunct program had awarded several journalists up to $\$ 20000$ each to investigate stories that often go unreported because of tight newsroom budgets and skeleton staffing.

"I have plenty of ideas for health reports, but if they require travelling I can almost forget them immediately," says Marine Corniou, who won a 2013 Canadian Medical Association (CMA) Media Award for her CIHR-funded report on the re-emergence of tuberculosis in Inuit communities. "Without financial help, we cannot go outside our offices, into the field, to report on health subjects."

Instead, CIHR will shift focus to less formal methods of sharing research with Canadians, including social media and public meet-and-greets with scientists. The agency will also host networking events to connect journalists and researchers.

However, Corniou contends that such events are a poor substitute for directly funding comprehensive health reporting. "I have no trouble to write emails or pick up my phone to connect with researchers."

Other grant recipients argue desk journalism simply isn't comparable to work done in the field.

Dominique Forget used the funds to trace emerging diseases to their origins in the Cameroon bushmeat trade. Like Corniou, she won a 2013 CMA Media Award for the story. "It's one thing to theorize what we can do to stop emerging disease, and another to actually meet the people who hunt and eat this meat. One hunter told me, 'You're worried about viruses. I'm worried about feeding my family.' You realize prob-

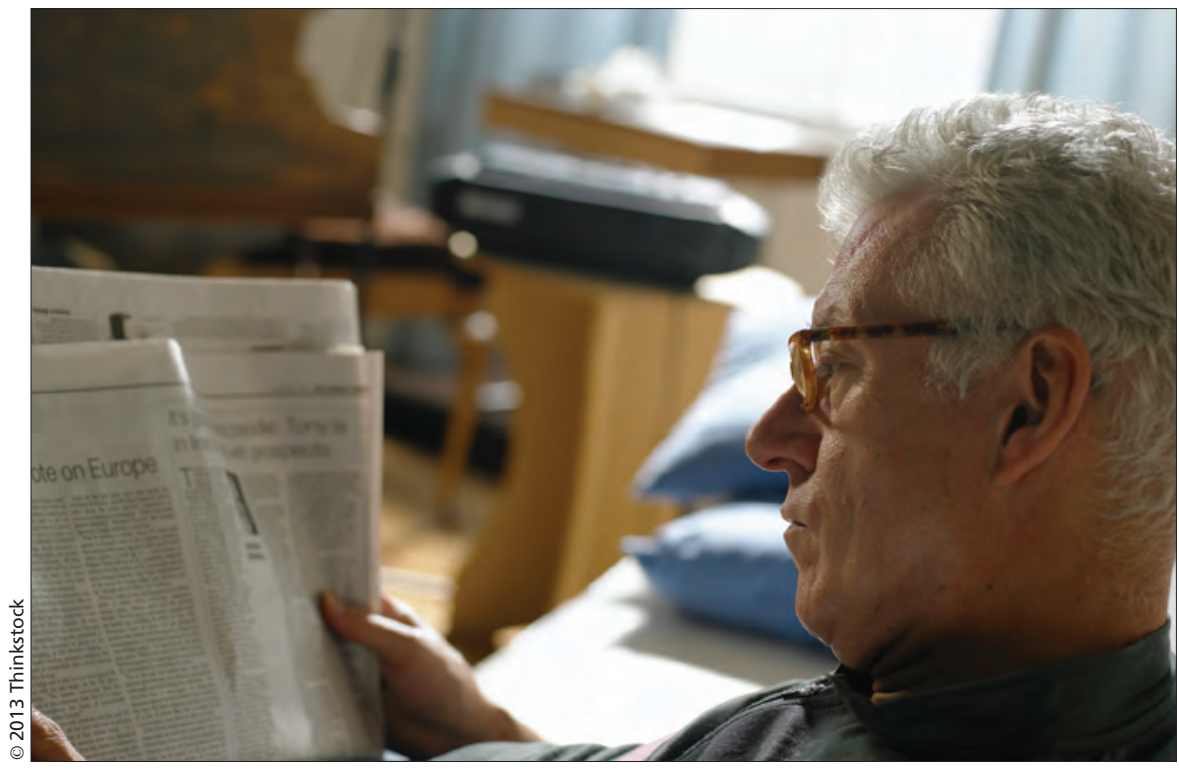

Canadians can expect to see fewer health stories about complex research or marginalized communities in the media as funds dry up for in-depth reporting, warn journalists.

lems are much more complex than they first appear."

The many accolades that past CIHR grant winners have received for their work reflects the value of the funding, adds Forget. Although there are still some funding opportunities for international stories, she laments there are few to none for reporting on marginalized communities closer to home.

Fellow grant recipient Catherine Dubé worries that coverage of health issues affecting First Nations and Inuit people is bound to get lost in the shuffle. She won a 2013 CMA Media Award for her story about the growing burden of hearing problems among people in the North.

"I was living with an Inuit woman, so all the moments I spent with her, even talking about other things, were important to understanding her community in a better way," she explains. Another magazine "did the same topic the year before, but the journalist couldn't go there, so it was just a one-page story. You can have the numbers and understand it's a big issue, but it's not alive."
How CIHR weighed the impact of such projects in its decision to cut the grants is unclear. According to the agency, it only required award recipients to submit a final report of all stories produced using the funds.

Ironically, a senior scientist cites the success of the program as a reason for its termination.

"There's some capacity that's built up now on some of the health reporting that's come out of that [program], and we're looking at other ways to support the connection between journalists and scientists," said Nancy Edwards, scientific director at CIHR's Institute of Population and Public Health, at an Oct. 9 forum on improving health reporting.

"Certainly the journalism awards were a means to achieve that end," said Edwards. However, "there's a variety of approaches that can be used. We don't really know which of these is most effective." - Lauren Vogel, CMAJ

CMAJ 2013. DOI:10.1503/cmaj.109-4638 